\title{
As ciências sociais e a cultura
}

\author{
RENATO ORTIZ
}

RESUMO: O artigo analisa a constituição histórica da cultura como objeto nas ciências sociais, em termos de cultura popular, cultura nacional e cultura de massa. Compara os processos de institucionalização da sociologia segundo seus diferentes contextos nacionais ou regionais, abordando os modos como a disciplina torna-se autônoma por meio da especialização de tarefas em concorrência com outras disciplinas. A retomada da unidade interpretativa e uma revisão conceitual para a abordagem dos "objetos globais" são definidos como os principais desafios para a sociologia na atualidade.

abemos que as Ciências Sociais se constituem como um universo autônomo, isto é, distinto de outras formas discursivas (senso comum, religião, política, filosofia, literatura, etc.), apenas no final do século XIX. Porém o estudo da cultura, como esfera temática diferenciada, encontra-se ainda nesse momento pouco desenvolvido. A Sociologia tem interesses mais prementes, o que se expressa nos objetos escolhidos pelos principais autores e correntes de pensamento da época: sociedade versus comunidade (Tonnies), divisão do trabalho (Durkheim), ética e capitalismo (Weber), mercadoria (Marx), industrialização e urbanização (Escola de Chicago). Há no entanto uma dimensão que irá chamar a atenção dos pesquisadores: o mundo da grande arte. Fruto das transformações ocorridas nesse mesmo século, a Arte (com maíuscula), como campo específico voltado para o universo restrito de seus pares, se consolida como um importante marco de referência a ponto da noção de cultura com ela se confundir (cf. Bourdieu,
PALAVRAS-CHAVE: cultura, sociologia, ciências sociais.

Professor do Departamento de Sociologia do IFCH-UNICAMP 
1996; Williams, 1983). Os termos culto e cultivado traduzem bem esta associação revelando as características de "superioridade" do mundo artístico em relação a outros domínios da sociedade. Uma forma de se perceber isso encontra-se na dicotomia cunhada pelos pensadores alemães: Kultur versus civilização. A Kultur corresponderia à esfera mais "elevada" da razão e do espírito; nela o indivíduo, o "ser humano", se realizaria por inteiro (cf. Elias, 1990). Caberia à civilização contentar-se com o lado material, industrial, técnico, portanto, "menor" das sociedades modernas. Existiria pois uma contradição insuperável entre essas duas dimensões antagônicas da vida. Durante o século XX, um conjunto de análises irá fundar uma nova especialidade, a Sociologia da Cultura, que basicamente se confunde com a "alta cultura" (penso nos trabalhos de Lucien Goldmann e de Levin Schucking). A literatura e a pintura desfrutam assim de um estatuto privilegiado, transformando-se em padrão de avaliação, de mensuração, das outras expressões culturais existentes. Dito de outra forma, a esfera artística não constitui simplesmente um universo autônomo, ela é alçada à posição de parâmetro ideal na compreensão de toda qualquer manifestação cultural (cf. Lowenthal, 1984). Um exemplo, o debate sobre o surgimento da cultura de massa nos Estados Unidos (anos $40 \mathrm{e}$ 50). Nele, a Arte é o divisor de águas das opiniões conflitantes, ela é referência obrigatória, ao ser criticada como elitista (pelos autores liberais vinculados à idéia de democracia de massa e ao mercado), ou idealizada como derradeiro refúgio da liberdade espiritual (os frankfurtianos) (cf. Jacobs, 1964; Horkheimer, 1941).

Duas outras disciplinas se dedicam ainda à problemática cultural: a História, com os estudos das civilizações, e a Antropologia, voltada para as sociedades indígenas. Civilização tem no entanto um outro significado; já não mais se contrapõe à Kultur, enquanto expressão da Arte e do Espírito, mas encerra um conjunto de valores modais constitutivos da identidade dos povos. Fernand Braudel observa que o termo, conjugado no singular na idade das Luzes, com a entrada no século XIX se pluraliza (cf. Braudel, 1991). Fala-se assim da civilização de Atenas, francesa, islâmica; elas seriam formadas por um conjunto de caracteres específicos a um grupo social vivendo numa determinada época. A proposta de Alfred Weber pode ser tomada como exemplar, pois condensa uma série de considerações que se fazem sobre as diversas civilizações que teriam composto a história da humanidade (cf. Weber, 1991). Cada uma delas representaria assim uma cultura modal, ocuparia uma área geográfica delimitada e moldaria das relações sociais ao seu destino histórico. É dentro dessa perspectiva que Spengler escreve A decadência do ocidente e Toynbee se dedica à composição de sua obra monumental sobre o significado das civilizações passadas e contemporâneas (tendência que se revigora hoje, com a globalização) (cf. Spengler, 1964; Toynbee, 1970/71). A Antropologia, por sua vez, também se dedica à problemática cultural com os trabalhos de Tylor, Malinowsky, Radcliffe-Brown. O emprego do termo cultura se associa assim ao estudo dos povos "primitivos" em contraposição ao de civili- 
zação, aplicado pelos historiadores às sociedades ditas “evoluídas”. Com o culturalismo norte-americano, um passo a mais é dado, pois alguns autores irão propor a existência de uma Teoria da Cultura, matriz abrangente capaz de abarcar as expressões de todas as sociedades humanas. Cultura significaria nesse caso uma totalidade que abrangeria dos artefatos materiais aos universos simbólicos. Entretanto, malgrado essa ambição teórica, nunca concretizada e um tanto ilusória, os antropólogos confinaram seus estudos às sociedades indígenas, expandindo paulatinamente seus interesses ao mundo camponês e às manifestações culturais contrastantes com a modernidade "ocidental" (crenças mágico-religiosas, comunidades, etc.).

As Ciências Sociais irão se disseminar em diferentes países seguindo um padrão de trabalho em princípio universal. Não obstante, as "regras do método" devem se acomodar ao movimento de regionalização no qual temas e enfoques particulares são desenvolvidos. Isso fica claro quando se compara os objetos tradicionalmente privilegiados pelos pesquisadores. Enquanto na Europa e nos Estados Unidos, a Sociologia se ocupa de assuntos como divisão de trabalho, urbanização, industrialização, metrópole, racionalização, na América Latina nos encontramos diante de questões como mestiçagem, oligarquias, religiosidade popular, mundo rural. Se para os europeus e norte-americanos o fundamental foi explicar a modernidade, no caso latino-americano era a sua ausência, ou melhor, as dificuldades para construíla, que chamava a atenção. Para o debate que nos interessa, dois aspectos são importantes: cultura popular e questão nacional. Como bem o demonstra Peter Burke, o conceito de cultura popular nasce na virada do século XVIII com o romantismo alemão (cf. Burke, 1990). Os intelectuais românticos querem recuperar um saber perdido no tempo, o tesouro de um patrimônio ancestral nos marcos de uma cultura nacional. Durante o XIX, com a expansão do romantismo e a emergência de uma consciência folclórica, o estudo sobre a cultura popular dissemina-se em vários países. Entretanto, e este é o ponto que quero ressaltar, no final do século, com o processo de autonomização das Ciências Sociais, o Folclore (the lore of the people), enquanto campo de conhecimento, tende cada vez mais a se situar à margem das novas disciplinas: Sociologia, Antropologia e História (cf. Ortiz, 1992). A profissionalização das Ciências Sociais implica um padrão de legitimidade e de trabalho científico que se afasta do que os folcloristas consideravam como "Ciência", a rigor, uma semiciência (cf. Gennep, 1967). Nos países centrais, França, Inglaterra, a Alemanha industrializada, já distante do romantismo, no momento em que as disciplinas acadêmicas se institucionalizam no campo universitário, ocorre um movimento de marginalização do Folclore que deve ocupar a periferia do sistema de conhecimento.

O mesmo não se passa com os países do leste e do sul da Europa. Aí, o tema da cultura popular, aliado à questão nacional, irá florescer. Temos assim, nas Ciências Sociais "clássicas", fundadoras de toda uma tradição, uma ausência da temática da cultura popular. A Antropologia dedica-se ao 
estudo das sociedades indígenas, a Sociologia à modernização e a História à formação dos Estados nacionais. Por isso é raro encontrarmos nos escritos de autores como Durkheim, Weber, Sombart, Simmel, a temática em pauta. A tradição marxista caminha na mesma direção. Marx e Engels estão preocupados com a indústria, a mercadoria, a máquina, esse é o coração do sistema capitalista. De uma certa maneira, a própria crença na ideologia do progresso (que permeia o conjunto de autores da época) expele para a margem o que se considerava como sendo, apenas, "resquícios do passado". Os próprios folcloristas, ao criarem os museus de cultura popular, admitem que essas expressões culturais, diante do avanço da modernidade, encontram-se em franco declínio. Por isso é necessário salvá-las, preservando, como diz De Certau, la beauté du mort (cf. Certau, 1980). Não é portanto fortuito que, entre os marxistas, aqueles que virão se ocupar da problemática sejam os oriundos dos países "pouco desenvolvidos". Como Gramsci, para quem a questioni meridionale é crucial no entendimento da fratura intelectual e política existente no seio do Estado-nação. Na América Latina, o interesse pela cultura popular é semelhante ao que ocorre nos países periféricos europeus. A ausência da modernidade, ou seja, sua realização "incompleta", implica o corolário oposto, a riqueza das tradições populares (o que é visto como um entrave à modernização pelas elites dominantes). Mas, é preciso acrescentar, a existência das culturas indígenas e a herança africana tornam o quadro anterior ainda mais complexo. Posto que o mundo rural, o sincretismo religioso, a diversidade indígena e a mestiçagem nada têm de "resquícios do passado", sendo na verdade forças atuantes do presente, dificilmente essa dimensão da vida social poderia ser negligenciada. As expressões culturais tradicionais constituem, assim, referência obrigatória, como o mostra muito bem Jesus Martin Barbero em seu livro Dos meios às mediações, orientando o debate numa direção inteiramente distinta, também nos Estados Unidos, onde o conceito de cultura popular praticamente se identifica ao de "cultura de massa", isto é, aos bens culturais produzidos industrialmente (cf. Rosenberg \& White, 1957).

$\mathrm{O}$ outro aspecto que eu havia apontado diz respeito à questão nacional, mas para que não haja mal-entendidos, é importante qualificá-la. As Ciências Sociais nascem em contextos nacionais, por isso falamos em Sociologia francesa e alemã, ou em Antropologia britânica e norte-americana. Como já demonstraram vários autores que se dedicaram à sua história, elas vêm marcadas pelos debates políticos e intelectuais que se desenrolam nos países em que se desenvolvem e são gestadas. O tema da nação é igualmente importante para diversos pensadores, por exemplo, Marcel Mauss, que o explora a partir da categoria de "consciência coletiva", cunhada pela escola durkheimiana. Weber se interessa pela temática nacional assim como Durkheim, principalmente no momento da Grande Guerra Mundial, quando o internacionalismo é uma opção política oposta ao nacionalismo dos Estados-nação (cf. Durkheim, 1975). Entre os marxistas, durante a II Internacional, a temática é objeto de um debate acirrado no seio das correntes internacionalistas (cf. Mármora, 
1978). Entretanto, mesmo isso sendo verdadeiro, pode-se dizer que a problemática da nação não determina prioritariamente o conteúdo e a orientação das Ciências Sociais na Europa industrializada (certamente porque nesses países a nação, no final do XIX, já se encontra cristalizada de forma distinta do início do século). Nesse sentido é legítimo afirmar que a temática da cultura nacional, embora permeie o pensamento dos autores e esteja presente no horizonte intelectual da época, nunca é hegemônica, a ponto de caracterizar a produção científica como um todo. Modernidade, metrópole, industrialização, divisão do trabalho são temas que evoluem relativamente distantes da questão nacional.

O caso é distinto na América Latina. Porém, antes de considerá-lo, é importante frisar, não se trata de algo relativo à sua excepcionalidade. Também no Japão, o desenvolvimento das Ciências Sociais se faz em estreita correlação com o debate sobre a nacionalidade. Ser ou não ser japonês, o dilema entre ocidente e oriente, marca profundamente o pensamento nipônico, dando inclusive origem a uma tradição literária conhecida pelo nome de nihonjinron (cf. Yoshino, 1992). A autenticidade ou não da cultura nacional, sua descaracterização pelo contato com a modernidade "ocidental", a capacidade do país em atuar antropofagicamente (para usar uma expressão de Oswald de Andrade), selecionando e digerindo o que viria de "fora", do "estrangeiro", são discussões que se prolongam da Antropologia à História, passando pela Sociologia e pela Filosofia (cf. Ortiz, 2000). De uma certa forma, nos encontramos diante de um debate análogo ao que se desenrola na América Latina. Mas, a solução encontrada é distinta. Enquanto no Japão a modernidade é reinterpretada em termos da tradição anterior (budismo, confucionismo, grupos de família), na América Latina ela deve ser construída sem levar-se em consideração nenhuma herança "milenar". Por isso as elites, para se distanciarem de seu passado mestiço, tenderam às vezes a pensar que seus países deveriam "partir do zero", o que é certamente um equívoco. De qualquer maneira, retornando à questão nacional, pode-se dizer que ela irá condicionar o contexto intelectual, da universidade às artes, da política à literatura. A racionalização do aparelho de Estado, o fomento à industrialização, a necessidade de se "ultrapassar" as tradições populares, a superação do subdesenvolvimento, são temas que se articulam em torno da identidade nacional. Dilema que penetra as Ciências Sociais com um todo, dos diagnósticos ensaísticos como os de Rodó à teoria da dependência. A temática da cultura nacional, associada à da cultura popular, torna-se assim uma dimensão vital do pensamento latino-americano (cf. Zea, 1986). A busca da identidade é uma preocupação acadêmica e política pois encontra-se em causa o destino da nação. É dentro desse quadro que se desenvolve um tema em particular: a crítica ao colonialismo e ao imperialismo. Lembrando que o conceito foi cunhado por Hobson em 1902, a expansão imperialista implica a existência de uma relação desigual das forças sociais. A afirmação das culturas nacionais se faz assim em condições extremamente desfavoráveis. Um exemplo, a discussão 
O debate sobre a situação colonial teve importante implicações no pensamento latinoamericano. Apenas a título de exemplo, lembro o livro de Álvaro Vieira Pinto (1960).

2 Como os estudos que se fazem na área da comunicação sobre o imperialismo norteamericano. Ver Beltrán \& Cordona (1980) e Dorfman (1980).

As pesquisas de Lazarsfeld sobre o rádio são dessa época. (Radio research, New Yorque, Duell Sloan and Pearce, 1942). O conceito de "indústria cultural", de Adorno e Horkheimer, aparece pela primeira vez no livro A dialética do Iluminismo, publicado em 1944. sobre a situação colonial. ${ }^{1}$ Nela, colonizador e colonizado fariam parte de um mesmo sistema no qual o "Ser" da nação se encontraria alienado no "Ser do Outro", ou seja, junto ao poder colonialista. A colônia careceria portanto de autenticidade. Para romper essa cadeia de eventos a única alternativa seria o o surgimento de uma vontade "desalienadora", isto é, a tomada de consciência das contradições inerentes a essa situação desigual. O homem colonizado, ao compreender o fundamento de suas amarras, poderia, no âmbito das lutas nacionalistas, modificar sua sina, construir para si um outro caminho. A critica à dominação estrangeira, cujo corolário é a revitalização da cultura autóctone, preenche assim todo o campo intelectual, envolvendo as artes, o cinema, a cultura popular e a televisão. ${ }^{2}$

Uma outra dimensão importante das Ciências Sociais refere-se à análise da cultura de massa. A problemática emerge nos Estados Unidos nos anos 30/40, um momento em que são desenvolvidas pesquisas sobre os meios de comunicação procurando entender o impacto das mensagens junto às audiências e ao público. ${ }^{3} \mathrm{O}$ fato desses estudos florescerem nos Estados Unidos é sintomático. Enquanto os países mais industrializados da Europa encontramse mobilizados pela guerra, aí o debate intelectual tem como referência outra realidade: os filmes de Hollywood, o star-system, o rádio, a soap-opera, a publicidade. A verdade é que os Estados Unidos conhecem antes dos outros a "revolução" tecnológica-comunicacional, assim como suas implicações na esfera da cultura. Na Europa, particularmente num país como a França, os estudos sobre a cultura de massa são posteriores. O livro de Edgar Morin, L'esprit du temps, é de 1962, sendo que, ainda nos anos 60, Morin e Barthes fundam o Centre d'Étude de Communication de Masse que publica a revista Communication. É do mesmo período o Centre for Contemporary Cultural Studies em Birgmingham (1964), cuja presença será importante na futura criação dos Estudos Culturais. De uma certa forma, pode-se dizer que as análise feitas na América Latina acompanham esse movimento mais geral, pois o texto de Antonio Pasquali, Comunicacion y cultura de masas, é de 1963 (cf. Pasquali, 1976). Datam também desse período a criação das faculdades de comunicação, espaço que se especializa nos estudos sobre as indústrias culturais. Aemergência da temática, cultura de massas, corresponde a uma reorganização profunda do campo cultural. Cabe lembrar que nenhuma sociedade, antes do século XX, conheceu um tipo de instituição semelhante, na qual a organização da cultura encontra-se em grande parte separada da vida daqueles que a utilizam. Graças aos meios tecnológicos, os produtos elaborados industrialmente podem ser difundidos em escala ampliada. A indústria cultural funciona portanto como uma instituição social, competindo diretamente com outras instituições como família, religião, partidos políticos. Devido à sua abrangência, à expansão do mercado cultural, ela irá deslocar duas instâncias importantes da vida social: a cultura popular e a arte. Se, no século XIX, a relação entre arte e bens culturais industrializados (folhetim e fotografia) era tensa mas distinta e diferenciada, com o advento da cultura de massa, o 
universo artístico perde paulatinamente sua autonomia sendo redefinido pelos interesses mercadológicos (neste aspecto, as análises frankfurtianas estavam corretas). Mas também o pólo da cultura popular, particularmente na América Latina, será inteiramente reorganizado dentro desse novo contexto. Festas, artesanato, crenças, folguedos, quando não deixam de existir, são rearticulados pelos novos espaços culturais - televisão, publicidade, turismo, etc. (cf. Canclini, 1983). Também o debate sobre a cultura nacional ganha uma outra dimensão, principalmente ao longo dos anos 70 e 80, quando o densenvolvimento da indústria cultural é insofismável em países como Brasil, México, Venezuela e Argentina. Isso terá consequências importantes pois um novo elemento, o mercado, entra em cena, termo que praticamente inexistia quando se discutia a relação entre nação e política nas décadas de 40, 50 e 60.

Pierre Bourdieu, em seus estudos sobre o campo intelectual, sugere que uma das formas de compreendermos a história do pensamento social é considerarmos o seu processo de institucionalização (cf. Bourdieu, 1980). A análise sociológica ganha assim em abrangência, pois temas, abordagens, discussões teóricas tornam-se mais claros quando situados no contexto da formação dos universos acadêmicos. Evidentemente, não é minha intenção trabalhar de maneira exaustiva essa dimensão do problema, mas, creio, ela é sugestiva no entendimento da temática cultural. Retomo portanto o argumento com o qual iniciei este artigo, a autonomização das Ciências Sociais.

Comparando o que ocorre na Europa e nos Estados Unidos com a América Latina, fica evidente a existência de uma defasagem temporal. Durkheim, fundador da Sociologia francesa, isto é, interessado em compor uma disciplina com métodos e procedimentos específicos na construção do objeto sociológico, escreve As regras do metódo sociológico em 1895, e a formação da equipe do L'Année Sociologique é de 1898. Seu projeto de institucionalização das Ciências Sociais, construído em torno de uma equipe coesa de indivíduos (Mauss, Halbwachs, Granet), data portanto do final do XIX (cf. Ortiz, 1989). Nos Estados Unidos, a Universidade de Chicago cria um departamento de Sociologia em 1892, e os primeiros trabalhos na área sociológica, como os de Florian Znaniecki, Park, Burguess, Louis Wirth, são do início do século XX. Tanto na França quanto nos Estados Unidos, o desenvolvimento do sistema universitário, a criação de departamentos e institutos de pesquisa, irá multiplicar os nichos institucionais incentivando o florescimento de diferentes áreas acadêmicas. Nos anos 40/50, diversas escolas de pensamento, funcionalismo e culturalismo, nos Estados Unidos, marxismo e estruturalismo, na França, se apresentam como referências teóricas importantes no campo intelectual. Ora, na América Latina temos uma institucionalização "tardia" das Ciências Sociais. O caso brasileiro é sintomático. Até pelo menos a década de 40, a produção do pensamento sociológico se fazia dentro de um contexto em que literatura, filosofia, discurso político e beletrismo se misturavam. Tinha-se na verdade uma disciplina marcada pelo ecletismo e pelo ensaísmo, fundamentada em afirmações genéricas que prescindiam de um tra- 
balho sistemático de pesquisa. A rigor, não existia um espaço específico no interior do qual o saber sociológico pudesse se autonomizar, ele se espalhava pelas escolas de Medicina, de Direito e pelos Institutos Históricos Geográficos. Por isso é apenas na década de 50 que se inicia a consolidação de um campo autônomo da Sociologia no Brasil. A "escola paulista", representada pela figura de Florestan Fernandes, é dessa época. Seu texto, O padrão de trabalho científico dos sociólogos brasileiros (importante como marco metodológico na Sociologia brasileira) foi publicado em 1958. Nele, o autor tinha em mente uma formação intelectual que privilegiasse as normas, valores e ideais do saber científico (cf. Ianni, 1986; Arruda, 1995). Há algo de mannheimiano nessa perspectiva que trata o ethos da ciência como uma espécie de subcultura, mas importa sublinhar, ela tem o nítido propósito de diferenciar a Sociologia das outras falas, num momento em que imperava uma polissemia sobre a interpretação do social. Pode-se dizer o mesmo da Antropologia. Enquanto disciplina, sobretudo na sua versão etnográfica, ela certamente existia, mas apenas de forma incipiente, desenvolvendo-se em pontos distantes e desconectados do país e praticadas por um número bastante reduzido de pessoas (cf. Corrêa, 1995). Não se pode esquecer, no caso brasileiro, que o desenvolvimento de uma rede universitária de ensino superior, até 1968, era limitado. Na verdade, a institucionalização das Ciências Sociais se consolida nos anos 70 e 80 com a expansão das universidades e a emergência de um sistema nacional de pós-graduação (implantação dos mestrados e doutorados). Sei que é difícil, a partir da especificidade brasileira, generalizá-la inteiramente para o resto da América Latina, sabendo inclusive da diversidade existente em termos continentais. Mas penso que é possível dizer, pelo menos em linhas gerais, que a autonomização do campo das Ciências Sociais é tardia mas efetiva. Isso tem implicações nos temas e nas análises realizadas, aproximando-as e distanciando-as da realidade dos países "centrais" (utilizo o termo entre aspas pois com a globalização ele torna-se cada vez mais impreciso).

Falar em autonomização significa pensar as fronteiras. Para existirem, as Ciências Sociais devem se separar de outras formas de conhecimento. Na América Latina, a íntima relação entre pensamento e política, consubstanciada no debate sobre a questão nacional, foi também possível devido à fragilidade dessa autonomização. Sendo tênues, as fronteiras deixavam filtrar mais facilmente, no interior de sua territorialidade, problemas em princípio externos à sua lógica. Por isso, quando ainda hoje, tradicionalmente nos referimos ao "pensamento brasileiro", ou ao "pensamento latino-americano", nos vem à mente um quadro no qual a reflexão teórica vem marcada pela política. Algo semelhante ocorre com o universo da arte. O ideal flaubertiano, l'art pour l'art, requer uma separação radical entre o mundo artístico, autônomo, independente, e as coisas da vida. Ora, na América Latina temos o inverso. Devido à problemática nacional, a arte sempre foi "engajada" (no sentido que posteriormente Sartre deu ao termo), contaminada de política. Nesse sentido pode-se dizer que o dilema da identidade nacional levou a 
intelectualidade a compreender um conjunto de temas (subdesenvolvimento, modernização), e entre eles a cultura (nacional, imperialista e colonialista), como algo intrinsecamente vinculado a questões políticas. A discussão da identidade encerrava os dilemas e as esperanças relativas à construção nacional. Veremos que essa porosidade das fronteiras irá se alterar (como apontarei em seguida) mas, sublinho, ela constitui um traço particular das Ciências Sociais latino-americanas, distinguindo-as em parte da tradição européia e norte-americana. Isso não é uma dimensão apenas do passado, ela tem, a meu ver, inclusive consequiências no debate contemporâneo. Por exemplo, na assimilação dos Estudos Culturais. Originários da Inglaterra e dos Estados Unidos eles problematizam justamente a existência das fronteiras disciplinares. Diante do enrijecimento do conhecimento disciplinar, propõe-se uma abertura intelectual, o que me parece salutar. Entretanto, para se entender essa proposta, é necessário situá-la no contexto que lhe é próprio, a competição acirrada das disciplinas.

Particularmente nos Estados Unidos, com o processo exacerbado de especialização, a falta de comunicação entre os diversos campos de saberes torna-se, não apenas um elemento questionável, mas um dado objetivo no qual esse questionamento se desenvolve. O quadro é porém distinto na América Latina, o que pode, de uma certa forma, explicar porque eles têm dificuldade em se institucionalizar enquanto universo diferenciado de conhecimento (pelo menos no Brasil). Quero com disso dizer que, num contexto de institucionalização restringido, as fronteiras disciplinares nunca conseguiram se impor com a mesma força e rigidez como ocorreu nos Estados Unidos. Não houve tempo nem condições materiais para que isso acontecesse. Sem dúvida elas existem nas universidades e centros de pesquisa mas são mais porosas, flúidas permitindo uma interação maior entre os praticantes das Ciências Sociais. A passagem da Filosofia à Sociologia, da Ciência Política à História, da Antropologia à Comunicação, da Sociologia à Crítica Literária, não são casos de exepcionalidade, constituem quase que uma regra do campo universitário. Talvez por isso o ensaio, como forma de apreensão da realidade, sobretudo na tradição hispânica (e menos luso-brasileira), tenha sobrevivido ao processo de formação disciplinar. Pois é de sua natureza desrespeitar a formalidade dos limites estabelecidos.

A tradição das Ciências Sociais, nos seus diversos ramos disciplinares, confinava a esfera da cultura a certos generos específicos: na Literatura, à discussão estética; na Antropologia, à compreensão das sociedades indígenas, folclore e cultura popular; na História, à reflexão sobre as civilizações. Tanto na Europa quanto nos Estados Unidos, a Sociologia, quando se ocupava do tema, praticamente o restringia à esfera da Kultur. Pode-se ainda dizer que a análise dos fenômenos culturais desfrutava de um prestígio "menor" no campo intelectual. Com a institucionalização das Ciências Sociais, objetos como partidos políticos, Estado, modernização, industrialização e urbanização eram vistos como "mais importantes" do que os estudos referentes 
à cultura popular, às religiões, à cultura de massa. Certo, a esfera da "alta cultura" permanecia ilesa, pois era considerada como algo à parte, garantindo assim sua aura solitária. Mas, no geral, pode-se dizer que os estudos literários pouco tinham a ver com as análises sociológicas, a Antropologia dificilmente dialogava com a dimensão moderna da chamada "cultura de massa" e assim por diante. Mesmo na América Latina, guardadas as devidas proporções, esse movimento se reproduz. Contrariamente à Europa e aos Estados Unidos, a temática cultural, associada ao dilema da identidade nacional, foi uma preocupação permanente da intelectualidade. Nesse sentido, as análises empreendidas transbordaram os limites estabelecidos pelas Ciências Sociais européias e norte-americana. A constituição da nação implicava uma reflexão diferenciada. No entanto, na virada dos anos 60/70, com o processo de institucionalização das disciplinas, temas como desenvolvimento, modernização, transição democrática, dependência e classes sociais terão um apelo muito maior entre os cientistas sociais e um público mais amplo. É possível dizer que a tradição marxista, talvez de forma inconsciente, tenha nisso desempenhado um certo papel, pois a "superestrutura", enquanto reflexo, ou não, da "infra-estrutura", designava às manifestações culturais uma posição secundária. Dessa forma, a esfera da cultura passa a ser vista, não em sua totalidade, mas recortada segundo temas e disciplinas. A unidade interpretativa, postulada nas análises anteriores (penso nos escritos de Gilberto Freyre), se rompe, abrindo caminho para a especialização das tarefas.

Atualmente, em contraposição a essa tendência de compartimentalização, o universo da cultura passou a ser percebido como uma encruzilhada de intenções diversas. Como se constituísse um espaço de convergência de movimentos e ritmos diferenciados: economia, relações sociais, tecnologia, etc. Esse é um movimento recente, e para mim um aspecto altamente positivo no processo de renovação das Ciências Sociais (nesse sentido os Estudos Culturais desempenham certamente um papel positivo). Ele rompe com uma espécie de "fordismo intelectual" no qual as especialidades e as subdivisões disciplinares implicaram a preponderância de um saber fragmentado em relação a uma perspectiva analítica mais integradora dos fenômenos sociais. Fica em aberto porém a questão se, no futuro, esse domínio de reflexão irá ou não se constituir numa "área" específica, como advogam alguns proponentes dos Estudos Culturais. Pessoalmente, não creio que venha a existir, como se pensou no passado, uma "Teoria da Cultura", com uma coerência teórica capaz de abranger a compreensão de realidade como um todo, mas estou convencido que dificilmente esse espaço de convergência pode se circunscrever às fronteiras canônicas das disciplinas existentes.

Um outro aspecto diz respeito à problemática do poder. Tradicionalmente, as Ciências Sociais tenderam a identificá-lo com a política. Há evidentemente exceções que confirmam a regra, por exemplo, a sociologia da religião de Max Weber. Não obstante, o movimento dominante no pensamento sociológico (no sentido amplo do termo) foi considerá-lo como algo prefe- 
rencialmente vinculado ao universo da política. Por isso temas como Estado, governo, partidos, sindicatos e movimentos sociais tornaram-se hegemônicos entre os cientistas sociais. A cultura ficava um tanto à margem disso tudo. Novamente, diante desse quadro, a América Latina pode ser vista de forma distinta, mas é importante dimensionar as coisas para não cairmos em malentendidos. Sublinhei como a temática nacional vinha marcada pela política; nesse sentido, discutir cultura, de uma certa forma, era discutir política. Entretanto, isto posto, é importante qualificar o contexto no qual o debate era travado e apontar para as mudanças advindas desde então. Primeiro, a emergência de uma indústria cultural, particularmente em países como o Brasil, o México e a Argentina, redefine a noção de cultura popular, despolitizando a discussão anterior (tratei de maneira exaustiva esse aspecto em meu livro $A$ moderna tradição brasileira). Segundo, o Estado-nação era o pressuposto básico da argumentação desenvolvida. Terceiro, o movimento de institucionalização das Ciências Sociais, mesmo restringido, com a especialização das disciplinas, incentivou a separação entre compreensão da realidade e atuação política. As transformações recentes deslocam ainda mais a centralidade do Estado-nação, redefinindo a situação na qual são produzidas as Ciências Sociais. Muito do que se define por "crise política" associa-se às restrições impostas à sua atuação. Com o processo de globalização, ele se debilita cindindo o elo postulado entre identidade nacional e luta política. $\mathrm{O}$ deslocamento do debate, da identidade nacional para as identidades particulares (étnicas, de gênero e regionais) reflete essa nova tendência. Mesmo no quadro dos antigos países "centrais", pode-se dizer que as instâncias tradicionais da política perdem legitimidade ao se definirem quase exclusivamente em termos das fronteiras nacionais (a discussão sobre uma possível sociedade civil mundial é um sintoma disso) (cf. Held, 1997). Uma outra mudança, a meu ver profunda, diz respeito ao modo como a esfera da cultura passa a ser percebida. Na América Latina, como apontei antes, ela era vista como um espaço de ação política, mas não necessariamente, como entendemos hoje, um lugar de poder. Ou seja, as contradições existentes no seio das manifestações culturais eram imediatamente traduzidas em análises e propostas encampadas pelas instituições tradicionalmente consagradas ao "fazer política": governo, partidos, sindicatos, movimentos sociais. Creio que se torna cada vez mais claro a distinção entre poder e política, pois o poder, como algo imanente às sociedades, às relações sociais, nem sempre se atualiza enquanto política. Entre as manifestações culturais e as instâncias propriamente políticas existem mediações. Sem elas corre-se o risco de indevidamente "politizar" a compreensão analítica, deixando-se de lado aspectos importantes, às vezes definitivos, da constituição de alguns fenômenos sociais (estética, religião, etc.). De qualquer maneira, conceber a esfera da cultura como um lugar de poder significa dizer que a produção e a reprodução da sociedade passa necessariamente por sua compreensão (o que é distinto da idéia de "conscientização", muito em voga na América Latina nos anos 50 e 60). 
Um último elemento deve ser mencionado pois marca de forma definitiva a relação entre a esfera cultural e as Ciências Sociais. Refiro-me ao processo de globalização e de mundialização da cultura. É importante entender que, no seu contexto, o que está em causa é a própria noção de espaço. Se o espaço é, como diziam Mauss e Durkheim, uma representação social, decorre que ela se modifica com as mudanças da própria sociedade. A consolidação da modernidade-mundo, a presença dos meios tecnológicos de comunicação, a unificação dos mercados no seio de uma unidade integrada, global, altera radicalmente o substrato material no qual estão inseridas as culturas. O que requer uma outra perspectiva analítica em relação à sua comprensão. Os conceitos de cultura e civilização, tal como foram classicamente concebidos pela Antropologia e pela História, dificilmente se aplicariam na íntegra ao mundo contemporâneo. Portanto, noções como "território", "fronteiras", "local", "nacional", devem ser revistas. Isso não significa a superação do espaço, o seu fim, como às vezes apressadamente concluem alguns pensadores. Não é necessário imaginarmos a história como uma sucessão de desaparecimentos definitivos. Importa qualificarmos a situação presente e compreendê-la dentro de uma outra perspectiva. Nesse sentido, categorias como cultura popular e cultura nacional precisam ser, para utilizar uma expressão na moda, deconstruídas e, eu acrescentaria, reconstruídas, diante da nova realidade. O que é válido também para termos como imperialismo ou colonialismo cultural. Não estou sugerindo que as relações desiguais entre países tenham desaparecido, isso seria insensato, mas afirmo que tais categorias já não mais dão conta das próprias relações de poder num mundo globalizado. De alguma maneira, repensar seus próprios conceitos, definir problemáticas e objetos de estudo, essa é a tarefa das Ciências Sociais no século XXI. Seja na Europa, Estados Unidos, América Latina ou Japão. O que elas têm hoje em comumé que os "objetos globais" tornam-se uma preocupação de todos nós. Um panorama distinto do final do XIX, quando a modernidade era propriedade de alguns lugares, sendo objeto de reflexão apenas de algumas mentes privilegiadas.

Recebido para publicação em março/2002

ORTIZ, Renato. The social sciences and culture. Tempo Social; Rev. Sociol. USP, S. Paulo, 14(1): 19-32, May 2002.

KEY WORDS:

culture, sociology, social sciences.
ABSTRACT: This article analyses the historical constitution of culture as object in social sciences, in terms of popular culture, national culture and mass culture. It compares the processes of institutionalisation of sociology according to the different national and regional contexts and it looks at how this subject of study becomes 
autonomous through task specialization when competing with other disciplines. The regaining of the interpretative unit and a conceptual review for the study of 'global objects' are defined as the main challenges for sociology nowadays.

\section{REFERÊNCIAS BIBLIOGRÁFICAS}

ARrudA, Maria Arminda. (1995) A sociologia no Brasil: Florestan Fernandes e a escola paulista. In: Miceli, S. (org.) História das ciências sociais no Brasil. São Paulo, Sumaré, vol. 2, p. 107-231.

Beltrán, Luis Ramiro \& Cordona, Elizabeth Fox de. (1980) Comunicación dominada: Estados Unidos en los medios de América Latina. Mexico, Editorial Nueva Imagen.

Bourdieu, Pierre. (1980) Questions de sociologie. Paris, Minuit. . (1996) As regras da arte. São Paulo, Companhia das Letras.

Braudel, Fernand. (1991) Las civilizaciones actuales. Cidade do Mexico, Rede Editorial Iberoamericana.

Burke, Peter. (1990) Cultura popular na Idade Moderna. São Paulo, Companhia das Letras.

CAnclini, Nestor. (1983) As culturas populares no capitalismo. São Paulo, Brasiliense.

Certau, Michel de. (1980) La culture au pluriel. Paris, Ch. Bourgeois.

CorrêA, Mariza. (1995) A antropologia no Brasil: 1960-1980. In: MicelLI, S. (org.). História das ciências sociais no Brasil. São Paulo, Sumaré, vol. 2, p. 25-106.

Dorfman, Ariel. (1980) Reader's Nuestro que estás en la tierra: ensayos sobre el imperialismo cultural. Mexico, Editorial Nueva Imagem.

DurkHEIM, Émile. (1975) A ciência social e a ação. São Paulo, Difel.

ELIAS, Norbert. (1990) Da sociogênese dos conceitos de civilização e cultura. In: O processo civilizador. Rio de Janeiro, Zahar.

GenneP, Van. (1967) The semi-schollars. London, Routledge and Kegan Paul.

Held, David. (1997) Democracy and global order. London, Polity Press.

HorkHeIMER, Max. (1941) Art and mass culture. In: Studies in philosophy and social sciences.

IANNI, Octávio. (1986) Florestan Fernandes e a formação da sociologia brasileira. Introdução a Florestan Fernandes. São Paulo, Ática.

JACOBS, Norman. (1964) Culture for millions? Boston, Beacon Press.

LowentHal, Leo. (1984) Historical perspective of popular culture. In: 
Literature and Mass Culture, New Brunswick (New Jersey), Transaction Books.

MÁRMORA, Leopoldo (org.). (1978) La segunda internacional y el problema nacional y colonial. Vols. 1 e 2, Cidade do México, Cuadernos de Pasado y Presente.

ORTIZ, Renato. (1989) Durkheim: arquiteto e herói fundador. Revista Brasileira de Ciências Sociais, 4(11), outubro. . (1992) Românticos e folcloristas. São Paulo, Olho d'Agua.

. (2000) O próximo e o distante: Japão e modernidade-mundo. São Paulo, Brasiliense.

PASQuali, Antônio. (1976) Comunicación y cultura de masas. Caracas, Monte Avila Editores.

PInTo, Álvaro Vieira. (1960) Consciência e realidade nacional. Rio de Janeiro, Instituto Superior de Estudos Brasileiros.

Rosenberg, Bernard \& White, Manning (org.). (1957) Mass culture: the popular arts in America. New York, Free Press.

SPlenger, O. (1964) A decadência do ocidente. Rio de Janeiro, Zahar.

ToynbeE, A. (1970/71) Estudios de la historia. Madri, Alianza Editorial.

Weber, Alfred. (1991) Historia de la cultura. Cidade do Mexico, Fondo Economico.

Williams, Raymond. (1983) Culture \& society. New York, Columbia University Press.

Yoshino, Kosaku. (1992) Cultural nationalism in contemporary Japan. London, Routledge.

ZeA, Leopoldo (org.). (1986) America Latina en sus ideas. Mexico, Siglo XXI. 